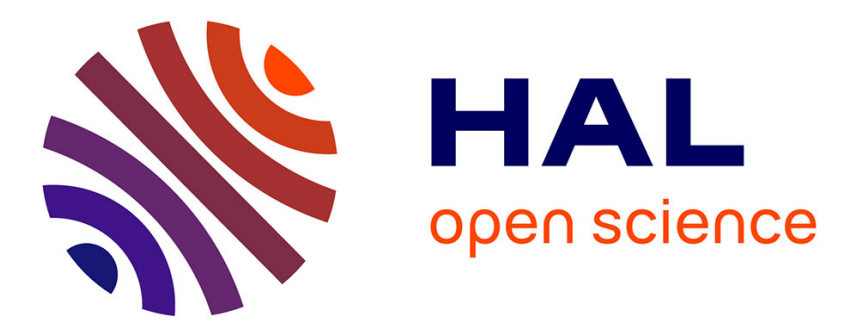

\title{
A pilot survey of aflatoxin-albumin adducts in sera from Egypt
}

Paul C Turner, Christopher Loffredo, Sharif El Kafrawy, Sameera Ezzat, Soheir Abdel Latif Eissa, Mai El Daly, Ola Nada, Mohamed Abdel-Hamid

\section{- To cite this version:}

Paul C Turner, Christopher Loffredo, Sharif El Kafrawy, Sameera Ezzat, Soheir Abdel Latif Eissa, et al. A pilot survey of aflatoxin-albumin adducts in sera from Egypt. Food Additives and Contaminants, 2008, 25 (05), pp.583-587. 10.1080/02652030701713939 . hal-00577434

\section{HAL Id: hal-00577434 \\ https://hal.science/hal-00577434}

Submitted on 17 Mar 2011

HAL is a multi-disciplinary open access archive for the deposit and dissemination of scientific research documents, whether they are published or not. The documents may come from teaching and research institutions in France or abroad, or from public or private research centers.
L'archive ouverte pluridisciplinaire HAL, est destinée au dépôt et à la diffusion de documents scientifiques de niveau recherche, publiés ou non, émanant des établissements d'enseignement et de recherche français ou étrangers, des laboratoires publics ou privés. 


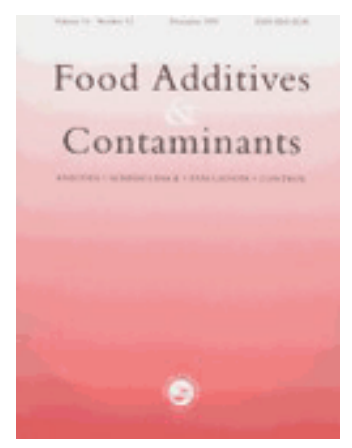

\section{A pilot survey of aflatoxin-albumin adducts in sera from Egypt}

\begin{tabular}{|r|l|}
\hline Journal: & Food Additives and Contaminants \\
\hline Manuscript ID: & TFAC-2007-300.R1 \\
\hline Manuscript Type: & Original Research Paper \\
\hline Author: & 26-Sep-2007 \\
\hline Complete List of Authors: & $\begin{array}{l}\text { Turner, Paul; University of Leeds, Molecular Epidemiology Unit, } \\
\text { Leeds Institute of Genetics, Health and Therapeutics } \\
\text { Loffredo, Christopher; Lombardi Cancer Center, Georgetown } \\
\text { University } \\
\text { El Kafrawy, Sharif; National Liver Institute, Menoufiya University } \\
\text { Ezzat, Sameera; National Liver Institute, Menoufiya University } \\
\text { Eissa, Soheir; National Cancer Institute, Cairo University } \\
\text { El Daly, Mai; National Liver Institute, Menoufiya University } \\
\text { Nada, Ola; Ain Shams University } \\
\text { Abdel-Hamid, Mohamed; Minia University }\end{array}$ \\
\hline Methods/Techniques: & Exposure assessment, Immunoassays \\
\hline Additives/Contaminants: & Aflatoxins, Mycotoxins \\
\hline Food Types: & \\
\hline &
\end{tabular}

\section{SCHOLARONE Manuscripts}




\section{A pilot survey of aflatoxin-albumin adducts in sera from Egypt}

2

3 Keywords: aflatoxin, aflatoxin-albumin, biomarkers Egypt, serum

4

5 Short title: aflatoxin-albumin adducts in Egyptian sera

6 Abbreviations: aflatoxin $\mathrm{B}_{1}\left(\mathrm{AFB}_{1}\right)$, aflatoxin $\mathrm{M}_{1}\left(\mathrm{AFM}_{1}\right)$, aflatoxin-albumin (AF-alb),

7 hepatocellular carcinoma (HCC), hepatitis B virus (HBV), hepatitis C virus (HCV), 


\section{Abstract}

2 Aflatoxins are potent liver carcinogens that frequently contaminate dietary cereals

3 within developing regions. Aflatoxin exposure has been predicted within Egypt but to

4 date no studies have measured the level of aflatoxin-albumin (AF-alb) adducts as a

5 validated biomarker to assess exposure. A limited number of sera were available from

6 an hepatocellular carcinoma (HCC) case control study within Egypt. In this pilot survey

7 AF-alb was detected in 24/24 samples from individuals without HCC diagnosis

8 (geometric mean $9.0 \mathrm{pg} / \mathrm{mg}$ range $3.5-25.8 \mathrm{pg} / \mathrm{mg}$ ), whilst $7 / 22$ samples from HCC cases

9 had detectable AF-alb (geometric mean 2.6pg/mg (range nd - 32.8pg/mg). These AF-

10 alb data do not represent a case control comparison due to inherent difficulties in

11 comparing markers of dietary intake between controls and patients with disease.

12 Although these data are limited, the potential health consequences of aflatoxin exposure

13 in this region merit further investigation. 


\section{$1 \quad$ Introduction}

2 Aflatoxins are metabolites of Aspergillus flavus and parasiticus which contaminate

3 common dietary staples during both cultivation and storage post-harvest (IARC 2002).

4 The most common and toxic of the naturally occurring aflatoxins is aflatoxin $\mathrm{B}_{1}$ $5 \quad\left(\mathrm{AFB}_{1}\right)$, and has been classified as a class 1A human liver carcinogen by the

6 International Agency of Research on Cancer (IARC 2002). The highest aflatoxin

7 exposures have been observed in parts of Africa, China and Southeast Asia, areas which

8 are also characterized by a high incidence of hepatocellular carcinoma (HCC) (IARC

9 2003). HCC is the fifth most common cancer in the world with around 500,000 new

10 cases annually, and HCC represents the third most common cause of cancer mortality in

11 the world (IARC 2003). The main risk factors for HCC in addition to aflatoxin are

12 hepatitis B virus (HBV) and hepatitis C viruses (HCV) (IARC 1994, 2002). Given the

13 burden of HCC in many regions of the world with mortality rates only slightly lagging

14 incidence rates, it is important to understand the contribution of all putative etiological 15 agents within a given region. In Egypt the prevalence of $\mathrm{HCC}$ is increasing (El-Zayadi 16 et al., 2005), and deaths due to HCC more than doubled in the previous two decades 17 increasing from 2.4 per 100,000 in 1987 to 5.2 per 100,000 in 2000 (El-Sawry et al., 18 2001). Major etiological factors in this region are clearly HCV (Angelico et al., 1997;

19 Saeed et al., 1991; El-Zayadi et al. 2005, El-Kafrawy et al. 2005) and HBV (Attia, 20 1998), with a possible independent role for occupational pesticide exposures (Ezzat et 21 al. 2005). To date the potential role of aflatoxins in HCC development in Egypt has not

22 been fully explored. We recently reported that 8 of 41 liver samples from Egyptian HCC cases contained a specific transversion mutation (AGG to AGT (arginine-to24 serine) at codon 249) within the TP53 tumour suppressor gene (TP53 Ser249) (El-

25 Kafrawy et al., 2005). This specific mutation is suggestive of aflatoxin being causative 
1 for the mutation (Bressec et al., 1991; Hsu et al., 1991; Kirk et al., 2000). In response,

2 we have undertaken a pilot biomarker survey to further assess the prevalence of 3 aflatoxin exposure within Egypt. The level of aflatoxin-albumin (AF-alb) adduct in 4 serum reflects the biologically effective aflatoxin dose, and serves as a useful aflatoxin 5 exposure biomarker in humans (Sabbioni et al., 1987, Chapot and Wild 1991; Wild and 6 Turner 2002). Moderate levels of aflatoxin exposure are predicted in Egyptian 7 populations based on measures of the parent aflatoxins (or phase 1 metabolites) in 8 biofluids (El-Nezami et al., 2000; Hatem et al., 2005; Hassan et al., 2006; Polychronaki 9 et al., 2006, 2007a, 2007b). However, to date there has not been an assessment of 10 aflatoxin exposure in Egypt using the more robust measure of the level of AF-alb 11 adducts in serum. The AF-alb adduct is particularly valuable in this respect as it 12 provides a good indicator of exposure over the previous two the three months 13 (Montesano et al., 1999; Wild and Turner 2002). This manuscript describes an 14 exploratory study in which the levels of AF-alb were measured for a subset of sera from 15 individuals within an Egyptian HCC case-control study, previously reported by Ezzat et 16 al., (2005). The prevalence and levels of exposure in this pilot study were compared to 17 exposure patterns reported elsewhere.

19 Methods

20 Subject Recruitment

21 A case-control study was conducted from 1999 - 2004 to study viral and environmental 22 risk factors associated with hepatocellular carcinoma (HCC) in Egypt. Detailed methods 23 of recruitment have been previously documented (Cowgill et al. 2004; Ezzat et al. 24 2005). In brief the study consisted of 343 confirmed cases of HCC and 524 non-cancer 25 controls matched by age, sex, and region of current residence. A subset of 46 
1 individuals, including 22 cases (aged 36-74; 18 males, 4 females) and 24 controls (aged

2 37-73; 20 males, 4 females), for whom blood samples were available, were tested for

3 the level of serum AF-alb adduct. All of these individuals were from the Cairo

4 metropolitan area or governorates within the Nile Delta, and all were HBsAg negative.

5 The subset of cases for this AF-albumin study were selected because they had TP53

6 gene mutation results available from a previous analysis (El-Kafrawy et al. 2005);

7 controls were randomly selected from the total pool of controls to match these cases on

8 age, gender and region distributions. However, due to difficulties in comparing

9 biomarkers related to dietary intake where one group are patients with disease, this

10 manuscript is not attempting to present case control data in relation to HCC causation.

\section{AF-albumin ELISA}

13 The levels of $\mathrm{AFB}_{1}$-albumin adduct were determined by albumin extraction, digestion 14 and ELISA as previously described (Chapot and Wild 1991). The detection limit was

$153 \mathrm{pg} \mathrm{AFB}_{1}$-lysine equivalents per $\mathrm{mg}$ of albumin $(\mathrm{pg} / \mathrm{mg})$. Three positive and one 16 negative control samples were analyzed with each batch of samples. Samples were

17 measured in quadruplicate on two separate days; CVs were less than 25\%. AF-alb data were natural log transformed to better approximate a normal distribution. Table 1,

19 reports the percentage of Egyptian samples with detectable AF-alb, and for clarity

20 adduct levels are back transformed and presented as geometric means.

\section{Results and Discussion}

23 Aflatoxin is a potent hepatocarcinogen, and given that exposure can occur throughout

24 life it is important to understand the pattern of exposure in regions potentially at risk

25 from this toxin. AF-alb has been used as a specific biomarker of exposure in West 
1 African adults (Wild et al., 2000; Turner et al., 2005a; Dash et al., 2007) and children

2 (Turner et al., 2000, 2003, 2005b, 2007; Gong et al., 2002, 2004), and exposure based

3 on this biomarker is frequent and at high levels. By comparison, there is less

4 information from Egypt on aflatoxin exposure using biomarkers but levels are predicted

5 to be lower than in West Africa (El-Nezami et al., 2000; Hatem et al., 2005). In this

6 pilot study of Egyptian samples, AF-alb adducts were detected in 31 of $46(67.4 \%)$ of

7 the samples (geometric mean 5.0pg/mg (range non detectable to $32.8 \mathrm{pg} / \mathrm{mg}$ ), see Table

8 1. Of the 24 individuals without HCC, all were positive for AF-alb $(n=24$, geometric

9 mean $9.0 \mathrm{pg} / \mathrm{mg}$; range $3.5-25.8 \mathrm{pg} / \mathrm{mg}$. By contrast fewer individuals, 7 of $22(31.8 \%)$,

10 with HCC had detectable adducts, and overall adduct levels were lower $(\mathrm{p}<0.001)$ in

11 cases (geometric mean 2.6pg/mg; range non detectable to $32.8 \mathrm{pg} / \mathrm{mg}$ ). $\mathrm{HCC}$ is

12 frequently diagnosed late, and due to the advanced state of the disease it is known that

13 individuals diagnosed with $\mathrm{HCC}$ in Africa have modified or restricted diets, leading to

14 lower aflatoxin exposures (Kirk et al., 2005). Dietary surveys were not conducted

15 within this study to specifically address this issue. AF-alb adducts were not observed for

16 the eight HCC cases carrying the TP53 Ser249 mutation, which may again simply

17 reflect such changes in dietary intake for HCC cases. In addition, if aflatoxin exposure

18 were causative for the reported TP53 Ser249 mutations in these eight HCC cases, this

19 would be as a consequence of chronic exposure over years or decades, thus a measure of

20 recent exposure would not neccesarily correlate with the mutation (Kirk et al., 2005).

21 For the non HCC cases, a non-significant trend $(\mathrm{p}>0.05)$ towards higher adduct levels

22 was observed for those from rural areas (geometric mean $11.2 \mathrm{pg} / \mathrm{mg}$; 95\%CI: 7.7,

$2316.2 \mathrm{pg} / \mathrm{mg}, \mathrm{n}=9$ ) compared to those in urban areas (geometric mean $7.9 \mathrm{pg} / \mathrm{mg} ; 95 \% \mathrm{CI}$ :

$245.8,10.7, \mathrm{n}=15)$, possibly reflecting less varied diets and reliance on basic dietary

25 staples in rural settings, as observed in The Gambia (Wild et al., 2000). A similar but 
1 again non-significant trend was also observed within the cases (data not shown).

2 Numbers limit both the interpretation of this observation, and further analysis of the 3 data by age, sex, or seasonality.

4 A comparison of AF-alb adducts in this study and a number of other countries, 5 measured using the ELISA methodology, are made in Table 1. The frequency and level

6 of exposure in West African countries is clearly higher, and for many individuals in

7 West Africa the levels exceed 100pg/mg (Wild et al, 2000; Turner et al., 2007). A

8 similar high prevalence of AF-alb was reported for adults in Ghana (Dash et al., 2007),

9 however, differences in assay methodology restrict further comparison with their data.

10 Limited surveys in Western Europe revealed no positive samples for this adduct

11 (reviewed by Wild et al., 1993). The frequency and levels of exposure in these Egyptian

12 samples are therefore considered to be intermediate in comparison with the low risk and

13 high risk areas for exposure, and to be more in line with exposures recently observed by

14 Scussel et al., (2006) in Brazil, or previously reported from Thailand (reviewed by Wild 15 et al., 1993).

17 Urine samples and breast milk provide additional bio-fluids with which to monitor 18 aflatoxin exposure. $\mathrm{AFM}_{1}$ is a major metabolite of $\mathrm{AFB}_{1}$ and is the main aflatoxin that 19 is sequestered into breast milk following maternal exposure to $\mathrm{AFB}_{1}$ (Zarba et al., 1992; IARC 2002). The frequency of AF-alb in our present study are in line with recent 21 observations of aflatoxin $\mathrm{M}_{1}$ in breast milk samples from Egyptian mothers (Polychronaki et al., 2006) in which 138/388 (35.6\%) were positive for this metabolite. The difference in prevalence may reflect the longer half-life of the albumin adduct, approximately 3 weeks (Chapot and Wild, 1991), compared to $\mathrm{AFM}_{1}$. 
1 Depending on sex and geographic location within Egypt the HBV surface antigen

2 (indicative of current infection) was detected in 3-11\% of the total case-control study 3 population (Ezzat et al., 2005), and HBV was estimated to contribute $5-10 \%$ to the

4 burden of HCC in Egypt. In regions where co-exposure to aflatoxin and chronic carriage

5 of HBV infection occur, a synergistic interaction in the development of HCC has been

6 reported (Ross et al., 1992; Qian et al., 1994; Wang et al., 2001), with the relative risk

7 of HCC increasing up to 60-fold with co-exposure. Given the level of chronic HBV

8 carriage in Egypt, the significance of potential co-exposure to aflatoxin is of concern.

$9 \mathrm{HCV}$ accounts for nearly $90 \%$ of the HCC burden in Egypt (Ezzat et al., 2005),

10 however, to date no interaction between $\mathrm{HCV}$ infection and aflatoxin exposure are 11 reported in the literature.

12

13 The purpose of this survey was a pilot investigation of the prevalence of AF-alb 14 adducts, as a biomarker of aflatoxin exposure, within Egypt. To our knowledge the 15 measurement of this validated biomarker to assess exposure in this region has not 16 previously been reported. Our data indicate moderate levels of aflatoxin exposure is 17 occurring within this limited survey, though larger studies are needed to investigate both 18 the sources and potential consequences of exposure to this potent toxin in Egypt.

19

20 Acknowledgements

21 This study was supported by grant number R01CA85888 from the U.S. National 22 Institutes of Health, and grant number TSA R6/81/1 (ID RCP 02/58) from the Regional 23 Office for the Eastern Mediterranean, World Health Organization. Authors thank Mrs 24 Anne Sutcliffe for technical assistance. AS and PCT were supported by NIEHS Grant 25 No. ES06052. 
1 Table 1: Aflatoxin-albumin adducts in adults from selected countries.

2

\section{COUNTRY}

(n)

Ib (pg/mg)

Geometric Mean

(range)

\section{Prevalence of} positive samples

$(\%)$

\section{Egypt}

Total

HCC cases

5.0 (nd - 32.8)

$31 / 46$ (76)

Controls

2.6 (nd - 32.8)

7/22 (31.8)

9.0 (nd - 25.8)

24/24 (100)

\section{The Gambia}

Rural

Peri-urban

Guinea\#\#

The Gambia

$40.4(4.8-260.8)$

$61.8(57.3-66.7) \#$

272/272 (100)

Wild et al., 2000

$39.1(31.1$ - 49.1)\#

18.4 (nd-66)

83/84 (98.8)

245/250 (98) Turner et al., 2005b

Brazil*

$10.7(\mathrm{nd}-57.3)$

$31 / 59(62)$

Scussel et al., 2006

France/ Poland

0 (nd)

$0 / 74(0)$

Wild et al., 1993

3 nd. non-detected

$4 *$ Geometric means of positives only

5 \# Geometric means and 95\%CI

6 \#\# Data obtained for blood samples in Feb/Mar

$7 \quad \$$ - Infants aged 4 months old. 


\section{References:}

2

3 Angelico M, Renganathan E,Gandin C, Fathy M, Profili MC, Refai W, De Santis A, 4 Nagi A, Amin G, Capcaccia L, Callea F, Rapicetta M, Badr G, Rocchi G, 1997. Chronic 5 liver disease in the Alexandria governorate, Egypt: contribution of schistosomiasis and 6 hepatitis virus infections. Journal of Hepatology. 26: 236-243.

7

8 Attia MA. 1998. Prevalence of hepatitis B and C in Egypt and Africa. Antiviral 9 Therapeutics 3:1-9.

10

11 Bressac, B., Kew, M., Wands, J., and Ozturk, M. Selective G to T mutations of p53

12 gene in hepatocellular carcinoma from southern Africa. Nature 350:429-431, 1991.

14 Chapot B, and Wild CP. 1991. ELISA for quantification of aflatoxin-albumin

15 adducts and their application to human exposure assessment., p. 135-155. In M. Warhol,

16 D. van Velzen, and G. R. Bullock (ed.), Techniques in Diagnostic Pathology. Academic

17 Press, San Diego

19 Cowgill KD, Loffredo CA, Eissa SA, Mokhtar N, Abdel-Hamid M, Fahmy A,

20 Strickland GT. 2004 Case-control study of non-Hodgkin's lymphoma and hepatitis C

21 virus infection in Egypt International Journal of Epidemiology.33(5):1034-9.

22

23 Dash B., Afrivie-Gyawn E., Hubner H.J., Porter W., Wang J.S., Jolly P.E., Phillips T.D.

24 (2007). Determinants of the variability of aflatoxin-albumin adduct levels in Ghanaians.

25 J. Toxicol. Environ. Health A. 70(1):58-66 
1 El-Kafrawy SA, Abdel-Hamid M, El-Daly M, Nada O, Ismail A, Ezzat S, Abdel-Latif

2 S, Abdel-Hamid A, Shields PG, Loffredo C. 2005 p53 mutations in hepatocellular 3 carcinoma patients in Egypt. International Journal of Hygiene and Environmental 4 Health 208: 263-70.

5

6 El-Nezami H, Mykkänen H, Kankaanpaa P, Suomalainen T, Salminen S, Ahokas J.

7 2000. Ability of a mixture of lactobacillus and propionibacterium to influence the 8 faecal aflatoxin content in healthy Egyptian volunteers: a pilot clinical study. Bioscience 9 Microflora 19:41-45.

10

11 El-Sawy MT, Mohamed MK, Boutros SG, El Hosaini M, Ibraheim T, Boutros S,

12 Ahmed SS. The burden of disease and injury in Egypt. Ministry of Health

13 and Population: Cairo, Egypt, 2004.

15 El-Zayadi AR, Badran HM, Barakat EM, Attia Mel D, Shawky S, Mohamed MK, Selim

16 O, Saeid A. 2005. Hepatocellular carcinoma in Egypt: a single center study over a

17 decade. World Journal of Gastroenterology 11: 5193-5198.

19 Ezzat S, Abdel-Hamid M, Abdel-Latif E, Mokhtar N, Labib NA, El-Ghorory L, Mikhail 20 NN, Abdel-Hamid A, Hifnawy T, Stickland GT, Loffredo CA. 2005. Associations of 21 pesticides, $\mathrm{HCV}, \mathrm{HBV}$, and hepatocellular carcinoma in Egypt. International Journal of 22 Hygiene and Environmental Health 208: 329-339. 
1 Gong Y, Cardwell K, Hounsa A, Egal S, Turner PC, Hall AJ, Wild CP. 2002. Dietary

2 aflatoxin exposure and impaired growth in young children from Benin and Togo: cross

3 sectional study. British Medical Journal 325: 20-21.

4

5 Gong Y.Y., Hounsa A., Egal S., Turner P.C., Sutcliffe A.E., Hall A.J., Cardwell K.

6 Wild C.P. (2004) Post-weaning exposure to aflatoxin results in impaired child growth: a

7 longitudinal study in Benin, West Africa. Environmental Health Perspectives. 112(13)

$8 \quad 1334-8$.

9

10 Hassan AM, Sheashaa HA, Abdel Fatah MF, Ibrahim AZ, Gaber OA. 2006 Does

11 aflatoxin as an environmental mycotoxin adversely affect the renal and hepatic

12 functions of Egyptian lactating mothers and their infants? A preliminary report.

13 International urology and nephrology. 38(2): 339-42.

15 Hatem NL, Hassab HM, Abd Al-Rahman EM, El-Deeb SA, El-Sayed Ahmed RL. 2005.

16 Prevalence of aflatoxins in blood and urine of Egyptian infants with protein-energy

17 malnutrition. Food and Nutrition Bulletin 26: 49-56.

19 Hsu, I.C., Metcalf, R.A., Sun, T., Welsh, J.A., Wang, N.J., and Harris, C.C. Mutational

20 hotspot in the p53 gene in human hepatocellular carcinomas. Nature 350:427-428, 1991.

22 International Agency for Research on cancer (IARC) 1994, Hepatitis viruses,

23 monographs on the evaluation of carcinogenic risks to humans. IARC Sci. Publ. 59

24 Lyon, France. 
1 International Agency for Research on cancer (IARC). 2002. Some traditional herbal

2 medicines, some mycotoxins, naphthalene and styrene. Lyon, France: World Health 3 Organization, IARC. Report nr 82. 1-556 p.

4

5 International Agency for Research on cancer (IARC) (2003). Cancer in Africa:

6 epidemiology and prevention. Lyon (France): IARC Scientific Publication 153

8 Kirk GD, Camus-Randon AM, Mendy M, Goedert JJ, Merle P, Trepo C, Brechot C,

9 Hainaut P, Montesano R. 2000. Ser-249 p53 mutations in plasma DNA of patients with

10 hepatocellular carcinoma from The Gambia. Journal of the National Cancer Institute 92: $11 \quad 148-153$.

12

13 Kirk GD, Lesi OA, Mendy M., Szymanska K., Whittle H., Goedert J.J., Hainaut P., 14 Montesano R. (2005) 249(ser) TP53 mutation in plasma DNA, hepatitis B viral 15 infection, and risk of hepatocellular carcinoma. Oncogene24(38):5858-67.

16

17 Kirk GD, Camus-Randon AM, Mendy M, Goedert JJ, Merle P, Trepo C, Brechot C, 18 Hainaut P, Montesano R. 2000.. 249(ser) TP53 mutation in plasma DNA, hepatitis B 19 viral infection, and risk of hepatocellular carcinoma. Oncogene. ;24(38):5858-67.

21 Montesano R, Hainaut P, Wild CP. 1997 Hepatocellular Carcinoma: From gene to 22 public health Journal of the National Cancer Institute 89 1844-1851 
1 Polychronaki N, Turner PC, Mykkanen H, Gong Y, Amra H, Abdel-Wahhab M, El-

2 Nezami H. 2006. Determinants of aflatoxin M1 in breast milk in a selected group of

3 Egyptian mothers. Food Additives and Contaminants 23:700-708.

4

5 Polychronaki N, West RM, Turner PC, Amra H, Abdel-Wahhab M, Mykkanen H, El-

6 Nezami H. 2007a. A longitudinal assessment of aflatoxin $M_{1}$ excretion in breast milk of

7 selected Egyptian mothers. Food and Chemical Toxicology. 45: 1210-1215 .

8

9 Polychronaki N, Wild CP, Mykkänen H, Amra H, Abdel-Wahhab M, Sylla A, Diallo

10 M, El-Nezami H, Turner PC. (2007b) Urinary biomarkers of aflatoxin exposure in

11 young children from Egypt and Guinea. Food and Chemical Toxicology (in press).

12

13 Qian GS, Ross RK, Yu MC, Yuan JM, Gao YT, Henderson BE, Wogan GN, Groopman 14 JD. 1994. A follow-up study of urinary markers of aflatoxin exposure and liver cancer 15 risk in Shanghai, People's Republic of China. Cancer Epidemiology Biomarkers and 16 Prevention 3:3-10.

18 Ross RK, Yuan JM, Yu MC, Wogan GN, Qian GS, Tu JT, Groopman JD, Gao YT,

19 Henderson BE. 1992 Urinary aflatoxin biomarkers and risk of hepatocellular carcinoma.

20 Lancet, 339: 943-946.

21

22 Sabbioni G., Ambs S., Wogan G.N., Groopman J.D. (1990) The aflatoxin-lysine adduct

23 quantified by high-performance liquid chromatography from human serum albumin 24 samples. Carcinogenesis 11(11):2063-6. 
1 Saeed AA, Al-Admawi AM, Al-Rasheed A, Fairclough D, Bacchus R, Ring C, Garson

2 J. 1991. Hepatitis C virus infection in Egyptian volunteer blood donors in Riyadh. 3 Lancet 338: 459-460.

5 Scussel VM, Haas P, Gong YY, Turner PC, Wild CP. 2006 Study of aflatoxin exposure 6 in a Brazilian population using an aflatoxin-albumin biomarker. In Mycotoxins and

7 phycotoxins: Advances in determination, toxicology and exposure management. $\mathrm{Ed} \mathrm{H}$.

8 Njapau, S. Trujillo, H.P van Egmond, D.L.park pp197-202

9

10 Turner PC, Collinson AC, Cheung YB, Gong YY, Hall AJ, Prentice AM, Wild CP. 112007 Aflatoxin exposure in utero causes growth faltering in Gambian infants.

12 International Journal of. Epidemiolology. [Epub ahead of print]

14 Turner PC, Mendy M, Whittle H, Fortuin M, Hall AJ, Wild CP. 2000. Hepatitis B 15 infection and aflatoxin biomarker levels in Gambian children. Tropical Medicine and 16 International Health 5: 837-841.

Turner PC, Moore SE, Hall AJ, Prentice AM, Wild CP. 2003. Modification of immune

19 function through exposure to dietary aflatoxin in Gambian children. Environmental 20 Health Perspectives 111: 217-220.

Turner PC, Sylla A, Gong YY, Diallo MS, Sutcliffe AE, Hall AJ, Wild CP. 2005a.

23 Reduction in exposure to carcinogenic aflatoxins by postharvest intervention measures

24 in west Africa: a community-based intervention study. Lancet 365: 1950-1956. 
1 Turner PC, Sylla A, Kuang SY, Marchant CL, Diallo MS, Hall AJ, Groopman JD, Wild

2 CP. 2005b. Absence of TP53 codon 249 mutations in young Guinean children with high

3 afltoxin exposure. Cancer Epidemiology Biomarkers and Prevention 14: 2053-2055.

4

5 Wang JS., Huang T, Su J, Liang F, Wei Z, Liang Y, Luo H, Kuang SY, Qian GS, Sun

6 G. He X, Kensler TW, Groopman JD.. 2001. Hepatocellular carcinoma and aflatoxin

7 exposure in Zhuqing Village, Fusui County, People's Republic of China. Cancer

8 Epidemiology Biomarkers and Prevention 10: 143-146.

9

10 Wild CP and Turner PC. 2002. The toxicology of aflatoxins as a basis for public health 11 decisions. Mutagenesis 17: 471-481.

12

13 Wild CP, Jansen LA, Cova L, Montesano R. 1993. Molecular dosimetry of aflatoxin 14 exposure: contribution to understanding the multifactorial etiopathogenesis of primary 15 hepatocellular carcinoma with particular reference to hepatitis B virus. Environmental 16 Health Perspectives 99: 115-122.

Wild CP, Yin F, Turner PC, Chemin I, Chapot B, Mendy M, Whittle H, Kirk GD, Hall

19 AJ. 2000. Environmental and genetic determinants of aflatoxin-albumin adducts in the

20 Gambia. International Journal of Cancer 86: 1-7.

21

22 Zarba A, Wild CP, Hall AJ, Montesano R, Hudson GJ, Groopman JD. 1992. Aflatoxin

23 M1 in human breast milk from The Gambia, west Africa, quantified by combined

24 monoclonal antibody immunoaffinity chromatography and HPLC. Carcinogenesis 13: $25 \quad 891-894$. 